\title{
INFLUÊNCIAS DA EPISTEMOLOGIA FUNCIONALISTA NA PSICANÁLISE FREUDIANA
}

\author{
INFLUENCES OF FUNCTIONAL EPISTEMOLOGY ON FREUDIAN PSYCHOANALYSIS
}

\author{
Bruna Coutinho Silva*
}

\begin{abstract}
RESUMO
A presente comunicação tem como objetivo apresentar aspectos da epistemologia funcionalista presentes na psicanálise freudiana. Para tanto, primeiramente apresentamos a constituição do campo da filosofia da psicanálise, cuja inspiração constitutiva foi a filosofia da biologia, e cujo sentido foi a demarcação de um território teórico-metodológico singular. A filosofia da psicanálise possui duas direções, pelo menos: estabelecer a teoria freudiana como objeto da filosofia e apresentar as provocações e as interrogações que a teoria freudiana colocou à filosofia. Em seguida, caracterizamos em linhas gerais o funcionalismo e sua relação com o positivismo no campo da psicologia, em seu esforço de estabelecer-se como ciência. Posteriormente, apontamos as características que identificamos em determinados conceitos e formulações na psicanálise freudiana, que a aproxima da matriz funcionalista. Por fim, buscamos responder à questão proposta por esta comunicação, que se trata de identificar na psicanálise freudiana aspectos do funcionalismo, os quais se apresentam em conceitos fundamentais, em momentos da obra freudiana, como o entendimento da estrutura psíquica e das pulsões.
\end{abstract}

PALAVRAS-CHAVE: Funcionalismo. Epistemologia. Psicanálise freudiana.

\section{ABSTRACT}

This communication aims to present aspects of functionalist epistemology present in Freudian psychoanalysis. For that, first, we present the constitution of the field of the philosophy of psychoanalysis, whose constitutive inspiration was the philosophy of biology, and whose meaning was the demarcation of a unique theoretical-methodological territory. The philosophy of psychoanalysis has at least two directions: to establish Freudian theory as an object of philosophy and to present the provocations and questions that Freudian theory posed to philosophy. Then, we characterize functionalism and its relationship with positivism in the field of psychology in general, in its effort to establish itself as a science. Later, we point out the characteristics that we identified in certain concepts and formulations in Freudian psychoanalysis, which brings it closer to the functionalist matrix. Finally, we seek to answer the question proposed by this communication, which is to identify aspects of functionalism in Freudian psychoanalysis, which are presented in fundamental concepts, in moments of Freudian work, such as the understanding of the psychic structure and the drives.

KEYWORDS: Functionalism. Epistemology. Freudian Psychoanalysis.

\footnotetext{
* Graduanda PUC Minas. E-mail: bcoutinho.psi@gmail.com.
} 
Em seu texto O que a filosofia da psicanálise é e o que ela não é, Simanke (2010) afirma que Freud buscou demarcar cientificamente a psicanálise na esteira do movimento das ciências psicológicas, entre os séculos XIX e XX. No entanto, diferentemente da psicologia, a psicanálise " [...] preservou - mais talvez, que as demais teorias psicológicas ou que a maioria delas, pelo menos - o teor e a tonalidade característica das questões filosóficas implicadas em seus conceitos" (SIMANKE, 2010, p. 190). Inclusive, muitos conceitos freudianos abordam debates de longa data no campo da filosofia, como a própria hipótese do inconsciente.

Simanke (2010) parte do pressuposto de que a teoria psicanalítica precisa constituir sua própria epistemologia. Isso porque muitos autores e filósofos da ciência interpretaram a psicanálise a partir de referenciais externos, de modo a criticá-la e estabelecer fronteiras entre o que é ou não ciência. No entanto, esse é um modo equivocado de compreender a psicanálise, uma vez que ela se apresenta como um campo inovador de conhecimento, na contramão do positivismo.

Para estabelecer um paralelo ilustrativo com o desenvolvimento da filosofia da psicanálise, Simanke (2010) relata o caso da filosofia da biologia, que surgiu, inicialmente, como uma crítica ao projeto positivista de cientificidade, pois a biologia se deparara com fenômenos que escapavam a esse paradigma, confrontando a exigência de repensar-se enquanto ciência. Ademais, a filosofia da biologia passou a ser como que uma subdisciplina na filosofia das ciências, levando, inclusive, à diversificação de seu campo teórico e metodológico (como a sociobiologia, a psicobiologia, a neurobiologia, etc.).

A filosofia da psicanálise, em seu desenvolvimento como um campo disciplinar, de modo semelhante à filosofia da biologia, colocou a teoria freudiana como objeto da filosofia, ao mesmo tempo em que considerou as provocações e as interrogações que a teoria freudiana trouxe à filosofia. Simanke (2010) aponta, ainda, como a filosofia da psicanálise contribuiu para a crítica ao neopositivismo como paradigma dominante nas ciências; contribuição essa, ao nosso ver, que abriu precedentes para outros modos de se pensar e fazer ciências humanas e sociais, a partir de pressupostos compreensivos, narrativos, fenomenológicos, para citar alguns exemplos.

Com o crescimento da filosofia da psicanálise enquanto campo de pesquisa e reflexão, diversos trabalhos foram desenvolvidos,

[...] quer rumo a uma epistemologia mais geral, capaz de realmente avaliar as estratégias de conhecimento empregadas pela psicanálise e situar seu lugar no conjunto das ciências e suas afinidades com as ciências humanas elou as ciências 
naturais, quer em direção a outras tradições do pensamento filosófico, como a estética, a política, a teoria social, entre outras, com as quais a problemática própria da psicanálise leva a estabelecer pontos de contato e de interlocução (SIMANKE, 2010, p. 204-205, grifo nosso).

No intuito de reconhecer o primeiro rumo mencionado por Simanke (2010), que destacamos em itálico na citação, propomos neste trabalho a seguinte questão: é possível identificar na psicanálise freudiana aspectos do funcionalismo? Para responder a essa questão é preciso, inicialmente, caracterizar a matriz funcionalista, especialmente em sua relação com o campo da Psicologia.

A psicologia é um campo científico marcado por inúmeras influências e matrizes teóricas, desde as ideias primordiais advindas da filosofia grega (psyché ou anima) até sua constituição declarada como ciência no século XIX. Nesse movimento de composição, a psicologia bebeu de diversas fontes, como do mecanicismo, do empirismo, do estruturalismo, da fenomenologia. O funcionalismo foi uma matriz fundamental para a área, sobretudo no momento de sua constituição como ciência nos moldes do paradigma hegemônico naturalista e exato, cuja influência se faz sentir ainda hoje em certas teorias psicológicas.

A matriz funcionalista encontra-se na biologia, enquanto disciplina científica fundada entre os séculos XVIII e XIX. O reconhecimento nas espécies animais de: estruturas funcionalmente hierarquizadas e interdependentes; mecanismos de autorregulação compensatórios entre o meio interno e o ambiente externo, apontando também a capacidade de plasticidade dos organismos; evolução das espécies com base em critérios de adaptação morfológica e comportamental ao ambiente, em comparação a outras espécies - são fundamentos da biologia expressa pela "[...] teoria dos sistemas abertos que fornece o modelo formal das interações adaptativas dos seres vivos com seus ambientes” (FIGUEIREDO, 2008, p. 77). É importante notar, portanto, que a palavra chave do funcionalismo é adaptação.

É preciso considerar que a possibilidade de uma Psicologia científica se deu a partir da doutrina positivista, marcada pelo método experimental e objetivo, aos moldes das ciências naturais e exatas. Nesse sentido, a ciência corresponderia ao estado em que "os fatos se ligam então segundo ideias ou leis gerais de ordem inteiramente positiva, sugeridas ou confirmadas pelos próprios fatos [...], mas sem criar qualquer hipótese que não possa, algum dia, ser verificada pela observação" (COMTE, 1822, p. 82). E o objetivo de quaisquer ciências, além de estabelecer os princípios universais que regem os fenômenos estudados, é buscar promover o desenvolvimento humano a partir da previsão, para conduzir a humanidade à ordem e à 
regulação. Nesse sentido, Comte estabelece a função pragmática das ciências. Especialmente quando trata da física social, Comte estabelece o princípio das relações funcionais aplicadas ao estudo da sociedade, a partir da noção de que, em relação aos fatos sociais, é necessário “[...] estabelecer suas relações mútuas e [...] apreender a influência exercida por cada um deles sobre o conjunto do desenvolvimento humano" (COMTE, 1825, p. 152).

Além do positivismo, cumpre destacar o papel da etologia na composição da matriz funcionalista. Desde Darwin, há uma preocupação com o instinto e seu caráter adaptativo para as diferentes espécies. Darwin publicou sua obra principal em 1859 e seu impacto se fez sentir na Psicologia americana, ao introduzir a ideia da necessidade de adaptação do organismo ao seu meio para sua sobrevivência, bem como o fato de propor analisar a função dos comportamentos animais, observando variações entre uma mesma espécie (SCHULTZ; SCHULTZ, 2005). Nesse sentido, a etologia se ocupa de estudar as finalidades dos comportamentos, a partir da comparação entre espécies (distintas ou iguais) e da experimentação (FIGUEIREDO, 2008).

Quando se trata propriamente de sua influência na psicanálise, é preciso compreender que o funcionalismo se apresentou em determinados momentos do desenvolvimento da teoria freudiana. No entanto, de forma alguma pode ser reduzida a tal ou qual matriz epistemológica, dada sua originalidade constitutiva. Conforme afirma Figueiredo (2008, p. 95-96):

[...] a obra de Freud é tributária de diversas tradições. Há tradições filosóficas; há
tradições filológicas, teológicas e místicas (realçadas pela aproximação da psicanálise
com a hermenêutica e a linguística); e há tradições científicas, que são as mais
explicitadas: 'A psicanálise é uma ciência natural - o que mais poderia ser?', diz
Freud em 1925. Entre as tradições científicas com que Freud se familiarizou durante
sua formação de pesquisador e médico encontramos, lado a lado, uma fisiologia de
índole mecanicista e uma biologia funcionalista (em particular a Teoria da evolução).
Cabe realçar o fato de que, em que pesem suas origens, díspares e sua já comentada
riqueza, a psicanálise nada tem de eclética - as diversas inspirações foram integradas
a um conjunto original, o que torna marcante o limiar entre sua história e sua pré-
história, aonde as diversas origens conservam sua independência e ainda são passíveis
de análises isoladas.

Nesse sentido, não pretendemos reduzir a psicanálise à matriz funcionalista e sim identificar como alguns de seus conceitos possuem relações com essa matriz.

Com a psicanálise, os fenômenos psíquicos são explicados de forma integrada, de modo que nenhum pode ser tomado como fortuito; todos possuem funções, integradas à estrutura psíquica. Nesse sentido Figueiredo (2008) compreende essa vertente como "determinismo absoluto", pois tudo, inclusive o que é acidental ou aleatório, é explicado tendo em vista o todo 
funcional que é o inconsciente. "Um esquecimento, uma troca de palavras, uma pequena e inconsequente mania, um sonho e um sintoma neurótico não tem nada de casuais e possuem um sentido a ser decifrado, uma função na dinâmica da personalidade" (FIGUEIREDO, 2008, p. 96).

Na “Carta 52” (FREUD, 1990), Freud afirma estar tratando da hipótese da estratificação formativa do aparelho psíquico. Para tanto, formula uma representação deste, conforme ilustrado na Figura 1.

\section{Figura 1 - Esquema representativo do aparelho psíquico}

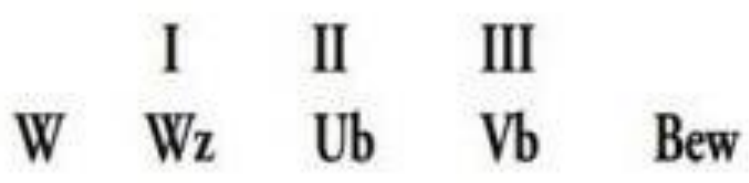

Fonte: Freud (1990)

A primeira camada é a percepção (W - Wahrnehmungen), formada pelos neurônios responsáveis por receber os estímulos internos. A segunda camada, primeiro registro, é a indicação da percepção (Wz - Wahrnehmungen zeichen), que são os sinais registrados que se associam por simultaneidade. A terceira camada é o inconsciente (Ub - Unbewusstsein), segundo registro, que funciona por deslocamentos e condensações e corresponde às lembranças conceituais ou conceitos. A quarta camada é a pré-consciência ( $\mathrm{Vb}$ - Vorbewusstsein), terceiro registro, correspondente à representação das palavras vinculada às lembranças conceituais ou conceitos. A passagem à consciência (Bew - Bewusstsein), por fim, é possível somente quando o conceito se associa à palavra. Essa representação de inconsciente o coloca como um estrato de partes ou camadas que possuem funções específicas na constituição do aparelho psíquico, operando de modo integral. Esse modo operatório, como vimos, é característico da matriz funcionalista.

Ainda na "Carta 52", Freud (1990) afirma que a sucessão entre as fases da vida está relacionada à sucessão dos registros psíquicos, de modo que, entre as fases, é preciso haver um processo de tradução do material psíquico. No entanto, como o processo de tradução libera desprazer, o recalcamento ocorre para impedi-la, ou seja, o recalque é uma "falha de tradução". Por isso é fundamental o trabalho sobre os mecanismos de repressão do ego, uma vez que estes impedem que o conceito (inconsciente) seja traduzido em uma palavra adequada, tornando-se 
consciente. Todo esse processo requer, como vimos, um trabalho psíquico intenso de integração entre elementos de naturezas distintas para que o funcionamento psíquico não seja patológico.

Outro conceito importante para nossa análise é a pulsão. Freud coloca que a pulsão, que está situada entre o corporal e o psíquico, implica satisfação ou descarga energética, para que a tensão psíquica em questão seja eliminada.

\footnotetext{
Voltando-nos agora para a consideração da vida psíquica do ângulo da biologia, o "instinto" nos aparece como um conceito-limite entre o somático e o psíquico, como o representante psíquico dos estímulos oriundos do interior do corpo e que atingem a alma, como uma medida do trabalho imposto à psique por sua ligação com o corpo (FREUD, 1996, p. 45).
}

No entanto, a possibilidade de satisfação pulsional está submetida à estrutura psíquica da personalidade, constituída por: uma instância que visa reprimir e censurar as pulsões, formada pelas leis morais, portanto, sociais, o superego; uma instância em que se encontram as pulsões em seu estado mais "puro", o id; e uma instância mediadora, o ego. O adoecimento advém justamente quando o ego não consegue regular de forma eficaz a pressão por satisfação pulsional advinda do $i d$ e a pressão por controle repressivo do superego.

\footnotetext{
O significado dos fenômenos patológicos é exatamente a função que desempenham na liberação e no controle da pressão mediante a expressão do desejo através de formas intencionalmente deformadas e destituídas de sentido aparente. Embora a saúde perfeita, como a felicidade, sejam ideais inatingíveis, como ideias reguladoras apontam para as formas mais eficientes e integradas de compatibilizar as exigências instintivas e as construções do mundo natural e social. (FIGUEIREDO, 2008, p. 9899).
}

Em se tratando das pulsões, é preciso considerar a primeira formulação freudiana acerca da dualidade pulsional, em que diferenciou dois tipos de pulsões: as pulsões sexuais, vinculadas ao princípio do prazer, ou seja, à busca pelo prazer e a evitação do desprazer; e as pulsões de autoconservação ou do ego, vinculadas ao princípio da realidade. Enquanto os objetos de satisfação da primeira podem ser fantasmáticos, os da segunda devem ser reais (GARCIAROZA, 2009). Como afirmam Barbosa e Santos (2005, p. 166): “A gênese e a evolução das pulsões sexuais e das pulsões do ego estão inseridas numa concepção de progresso constitutiva e situada dentro de um esquema único em que a adaptação aparece como finalidade". Tais pulsões operam, portanto, pela busca do equilíbrio entre as necessidades do sujeito e as possibilidades de sua realização. 
Em “Além do princípio do prazer", texto de 1920, Freud (1977) dá continuidade ao desenvolvimento de sua teoria pulsional. Incialmente, aborda a transformação da psicanálise no que diz respeito ao trabalho com o reprimido junto ao paciente: antes, apenas comunicava-se ao paciente; depois, comunicava-se ao paciente para este confirmar a interpretação. No entanto, Freud percebeu que o objetivo de tornar o inconsciente consciente não era possível de ser feito, completamente, pois o paciente não consegue recordar todo o material inconsciente reprimido. Ainda, a recordação desse material pode não estar associada ao seu núcleo, ou seja, ao desejo. Nesse caso, quando não é possível recordar, o paciente repete ou atua, reproduzindo seus conflitos sexuais advindos da vivência do complexo edípico.

O que Freud introduz como novidade nesse texto é que nem sempre o que é repetido compulsivamente é da ordem do prazer, tampouco em algum momento o foi. Ou seja, há uma força concorrente com o princípio do prazer, através da qual o paciente é levado a repetir e buscar o desprazer, repetição essa que remete a situações infantis vividas que nunca produziram satisfação. Aqui Freud introduz o entendimento sobre a pulsão de morte, como uma força desagregadora, tendendo à morte e à autodestruição, ou à busca pura pelo desprazer.

A construção teórica acerca do aparato psíquico é muito interessante por trazer justamente esse funcionamento integrado entre seus componentes em termos de interdependência: somente quando as resistências diminuem, é possível que o material reprimido possa ser associado à palavra e comunicado, associado à transferência branda e positiva com o analista. Cada momento do processo de elaboração do reprimido está articulado um ao outro como condição sine qua non para que ocorra de forma efetiva. Do mesmo modo, em se tratando da compulsão à repetição do desprazer na consciência, a saída envolve a busca na vida pregressa infantil dos elementos inconscientes — as injunções infantis — que o paciente não se dá conta, e que fazem com que seu projeto de vida seja um projeto de sofrimento. Todo o processo de elaboração psíquica, portanto, remete ao funcionamento de um todo funcional, em que cada etapa ou ação (recordações, repetições, transferência) exerce um papel fundamental para possibilitar a vinculação conceitual à palavra, levando à ruptura com a compulsão à repetição e com o estado patológico do cliente, em consequência, neste momento de sua vida e em relação aos aspectos que foram trabalhados em análise.

Como pudemos ver, algumas formulações conceituais na psicanálise freudiana contêm aspectos funcionalistas, como: os processos psíquicos exercerem funções de regulação pulsional do sujeito; a necessidade de que os componentes do aparelho psíquico operem de modo funcional e integrado para estabelecer um estado psíquico saudável; a importância da 
satisfação pulsional como forma de se alcançar um estado de equilíbrio, ainda que momentâneo; a integração entre os aspectos internos (necessidades) e externos (objetos no ambiente) na busca de compensação entre estes para a satisfação pulsional (pulsões sexuais e de autoconservação).

Os textos utilizados na disciplina, especialmente os que selecionamos aqui (FREUD, 1990; FREUD, 1977; SIMANKE, 2010) para dar suporte à nossa reflexão, se fizeram fundamentais para buscar responder à questão proposta por este texto, uma vez que abordam conceitos que nos permitiram vislumbrar elementos funcionalistas na psicanálise freudiana.

Reiteramos que não é possível reduzir a matriz da psicanálise freudiana ao funcionalismo, já que é um campo teórico-clínico vasto em termos de influências e perspectivas componentes, além de ser utilizada e discutida em vários campos de conhecimento, como a antropologia, a sociologia, a filosofia, entre outros. Portanto, podemos afirmar aqui que, no que diz respeito, sobretudo, ao entendimento da estrutura psíquica e das pulsões, em determinados momentos de sua formulação em Freud, encontramos os princípios funcionalistas apontados anteriormente.

\section{REFERÊNCIAS}

BARBOSA, Maria Nadeje Pereira; SANTOS, Manoel Antônio dos. Considerações sobre a Dimensão Biológica do Conceito de Pulsão em Freud. Psicologia: Reflexão e Crítica, Porto Alegre, v. 18, n. 2, p. 162-170, maio/ago. 2005.

COMTE, Augusto. Considerações filosóficas sobre as ciências e os cientistas (1825, p. 151155). In: BENOIT, Lelita O. Augusto Comte: fundador da física social. São Paulo: Editora Moderna, 2002a, p. 117-121.

COMTE, Augusto. Planos de trabalhos científicos necessários para reorganizar a sociedade (1822, p. 81-84). In: BENOIT, Lelita O. Augusto Comte: fundador da física social. São Paulo: Editora Moderna, 2002b, p. 114-117.

FIGUEIREDO, Luís Cláudio Mendonça. Matrizes do pensamento psicológico. 14. ed. Petrópolis: Vozes, 2008.

FREUD, Sigmund. Além do princípio de prazer. In: FREUD, Sigmund. Edição standard brasileira das obras completas de Sigmund Freud, v. 18. Rio de Janeiro: Imago, 1977, p. 12-85.

FREUD, S. Carta 52. In: FREUD, S. Edição standard brasileira das obras psicológicas completas de Sigmund Freud, v. 1. Rio de Janeiro: Imago, 1990, p. 317-324. 
FREUD, S. O instinto e seus destinos. In: FREUD, S. Obras Completas, volume 12 Introdução ao narcisismo, ensaios de metapsicologia e outros textos. (1914-1916). Tradução de Paulo César de Souza. São Paulo: Companhia das Letras, 1996, p. 38-60.

GARCIA-ROZA, Luiz Alfredo. Freud e o inconsciente. 24. ed. Rio de Janeiro: Jorge Zahar, 2009.

SCHULTZ, Duane; SCHULTZ, Sydney E. História da Psicologia Moderna. Tradução de Suely Murai Cuccio. 8. ed. São Paulo: Pioneira Thomson Learning, 2005.

SIMANKE, Richard Theisen. O que a filosofia da psicanálise é e o que ela não é. Educação Temática Digital, Campinas, v.11, n. esp., p.189-214, mar. 2010. Disponível em: https://periodicos.sbu.unicamp.br/ojs/index.php/etd/article/view/906/921. Acesso em: 16 out. 2019. 